\section{GOOD NEWS FOR HIV POSITIVE HEALTHCARE PROFESSIONALS}

The Department of Health (DH) has announced a system of health clearance for healthcare workers living with HIV whose disease is adequately controlled, so that they are able to return to their chosen profession.

Kevin Lewis, Dental Director, Dental Protection, said: 'We have been lobbying for a change to the regulations that recognised the latest evidence since 2005 and we know from first-hand experience that the intervening nine years have seen dental careers terminated at considerable cost (emotional and financial) for the individuals involved. I was glad to learn that our legal challenge to the Department accelerated the development of the new clearance procedure. It would not have been possible for us to pursue the legal challenge without the courage of the dental member who agreed to have their name used in this case.

For the dental profession in England this means that a number of people will now be able to return to work provided they comply with the details of the clearance procedure that is being overseen by Public Health (England).

For further details see: https://www.cas.dh.gov.uk/ ViewandAcknowledgment/ ViewAttachment. aspx?Attachment_id=101791.

\section{DISTINGUISHED SCIENTIST}

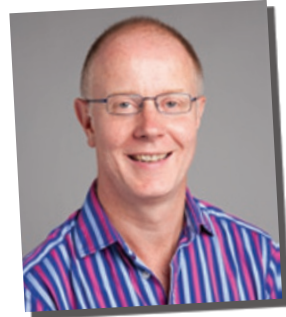

In recognition of his research achievements, Professor Richard Watt (Epidemiology and Public

Health) has been awarded the 2014

International Association for Dental Research (IADR) Distinguished Scientist Award for Behavioural, Epidemiologic and Health Services Research. His award will be presented at the IADR annual scientific meeting in Cape Town in June 2014.

\title{
INVESTIGATION
}

Like all professions, dentistry is changing and it seems students and young dentists have a less certain future ahead of them than those who were entering the vocation 50 years ago. With fewer practice owners and the rise of dental corporates changing the landscape for future independent practitioners, many young dentists will have to put aside their dream of buying a practice. But what are the alternate career paths to general dentistry and what jobs are available?

Becoming a practice owner is increasingly difficult in this economic climate, with a 2012 survey revealing $47.3 \%$ of practice owners setting up in the past five years experienced difficulties compared to $19.4 \%$ of those who had become practice owners more than five years ago. ${ }^{1}$ Borrowing or raising capital was the most common barrier reported to setting up a practice, by $33 \%$ of those who had set up a practice less than five years ago. ${ }^{1}$ However, a 2012 Business trends survey showed that nine out of ten practice owners that applied for a bank loan or credit were successful in their application. ${ }^{2}$

With increasing barriers to practice ownership, corporates can offer new career structures for dentists with diverse interests. Alex Handley, Recruitment and Marketing Manager for Genix Healthcare, suggests: 'Corporates offer a support network and career progression that isn't available elsewhere in the dental market.' Those taking an associate post from day one at Genix Healthcare have the future options to specialise, mentor or act as a clinical director. Yet the reality of how much corporates dominate the dental market may be very different to what is imagined. In 2012 the share of the market held by corporates was estimated to be only $10 \%$, with the vast majority of practices owned by individual dentists. ${ }^{1}$ Out of 68 NHS

\section{CAREERS IN DENTISTRY: ARE THERE STILL OPTIONS?}

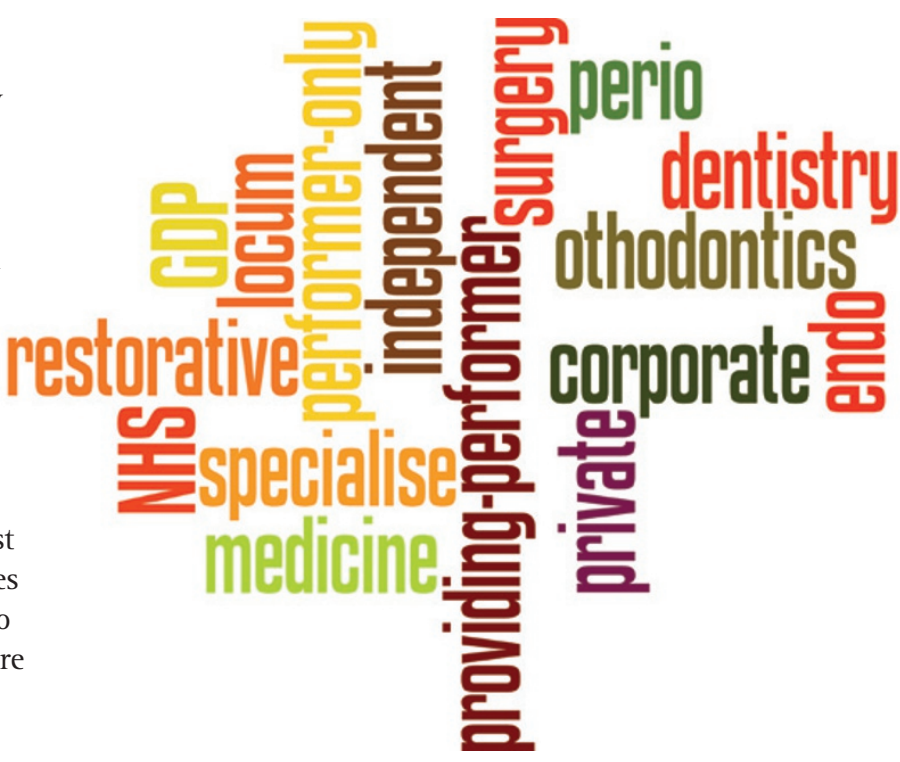

practices surveyed in Croydon, only two were owned by large dental corporates. In a national survey, less than one in 20 practice owners said that their main practice was owned by a corporate. ${ }^{3}$

Still, since 2007 the number of providing-performers has decreased by $38.7 \%$ and the number of performeronly dentists has risen by $47.5 \% .{ }^{1}$ Many enter the profession with hopes for autonomy and flexible hours but even as a practice principal or manager UDA targets within the NHS mean that it is difficult to work at your own speed.

Young dentist Surinder Poonian found that dental school did not fully prepare her for the challenges she faced in the immediate years after qualifying from the University of Sheffield in 2011: 'Career planning and finding a good job as an inexperienced practitioner can, in reality, be quite a daunting prospect'. After an associate position at an independent practice in North West London fell through, Surinder has been working as a locum and building on her experience. Now she is looking to possibly develop a career in special care dentistry with pain and anxiety control, taking a holistic approach to patient management: 'It may not be easy but I strongly believe that as young dentists we have the power and capacity to influence and shape the future of the dental profession and our own careers'.

The Centre for Workforce Intelligence published a strategic review in 2013 analysing the future 'supply and demand' of the dental workforce in England between 2012 and $2040 .{ }^{5}$ This revealed that there is likely to be a surplus supply of dentists by as much as 4,000 dentists by 2040 . Care must be taken in reducing dental school 